\title{
Spatial and Temporal Variability of Nonfreezing Drizzle in the United States and Canada
}

\author{
AdDison L. SeARs-COLLins* \\ Oklahoma Weather Center Research Experiences for Undergraduates, Norman, Oklahoma, and University of Virginia, \\ Charlottesville, Virginia \\ DAVID M. SCHULTZ \\ Cooperative Institute for Mesoscale Meteorological Studies, University of Oklahoma, and NOAA/National Severe Storms Laboratory, \\ Norman, Oklahoma \\ ROBERT H. JOHNS \\ Norman, Oklahoma
}

(Manuscript received 27 June 2005, in final form 7 November 2005)

\begin{abstract}
A climatology of nonfreezing drizzle is created using surface observations from 584 stations across the United States and Canada over the 15-yr period 1976-90. Drizzle falls 50-200 h a year in most locations in the eastern United States and Canada, whereas drizzle falls less than $50 \mathrm{~h}$ a year in the west, except for coastal Alaska and several western basins. The eastern and western halves of North America are separated by a strong gradient in drizzle frequency along roughly $100^{\circ} \mathrm{W}$, as large as about an hour a year over $2 \mathrm{~km}$. Forty percent of the stations have a drizzle maximum from November to January, whereas only $13 \%$ of stations have a drizzle maximum from June to August. Drizzle occurrence exhibits a seasonal migration from eastern Canada and the central portion of the Northwest Territories in summer, equatorward to most of the eastern United States and southeast Canada in early winter, to southeastern Texas and the eastern United States in late winter, and back north to eastern Canada in the spring. The diurnal hourly frequency of drizzle across the United States and Canada increases sharply from 0900 to 1200 UTC, followed by a steady decline from 1300 to 2300 UTC. Diurnal drizzle frequency is at a maximum in the early morning, in agreement with other studies.

Drizzle occurs during a wide range of atmospheric conditions at the surface. Drizzle has occurred at sea level pressures below $960 \mathrm{hPa}$ and above $1040 \mathrm{hPa}$. Most drizzle, however, occurs at higher than normal sea level pressure, with more than $64 \%$ occurring at a sea level pressure of $1015 \mathrm{hPa}$ or higher. A third of all drizzle falls when the winds are from the northeast quadrant $\left(360^{\circ}-89^{\circ}\right)$, suggesting that continental drizzle events tend to be found poleward of surface warm fronts and equatorward of cold-sector surface anticyclones. Two-thirds of all drizzle occurs with wind speeds of $2.0-6.9 \mathrm{~m} \mathrm{~s}^{-1}$, with $7.6 \%$ in calm wind and $5 \%$ at wind speeds $\geqslant 10 \mathrm{~m} \mathrm{~s}^{-1}$. Most drizzle $(61 \%)$ occurs with visibilities between 1.5 and $5.0 \mathrm{~km}$, with only about $20 \%$ occurring at visibilities less than $1.5 \mathrm{~km}$.
\end{abstract}

\section{Introduction}

Drizzle occurrence can provide important insight into the dynamics and microphysics of low-level clouds

\footnotetext{
* Current affiliation: Department of Meteorology, The Pennsylvania State University, University Park, Pennsylvania.

Corresponding author address: Dr. David M. Schultz, NOAA/ NSSL, 1313 Halley Circle, Norman, OK 73069.

E-mail: david.schultz@noaa.gov
}

(e.g., Stevens et al. 2005). Many previous drizzle studies have focused on the effect of cloud condensation nuclei on the growth and size distribution of drizzle droplets in marine stratocumulus and stratus clouds (e.g., Frisch et al. 1995; Feingold et al. 1996, 1999; Gerber 1996; Galloway et al. 1999; Ferek et al. 2000; Hudson and Yum 2001; Rasmussen et al. 2002; Stevens et al. 2003). For example, Ferek et al. (2000) observed a reduction in drizzle drops in ship tracks because of the increase in cloud condensation nuclei from the ships' emissions. Specifically, Albrecht (1989) argued that higher aerosol concentrations resulted in smaller cloud droplets, which 


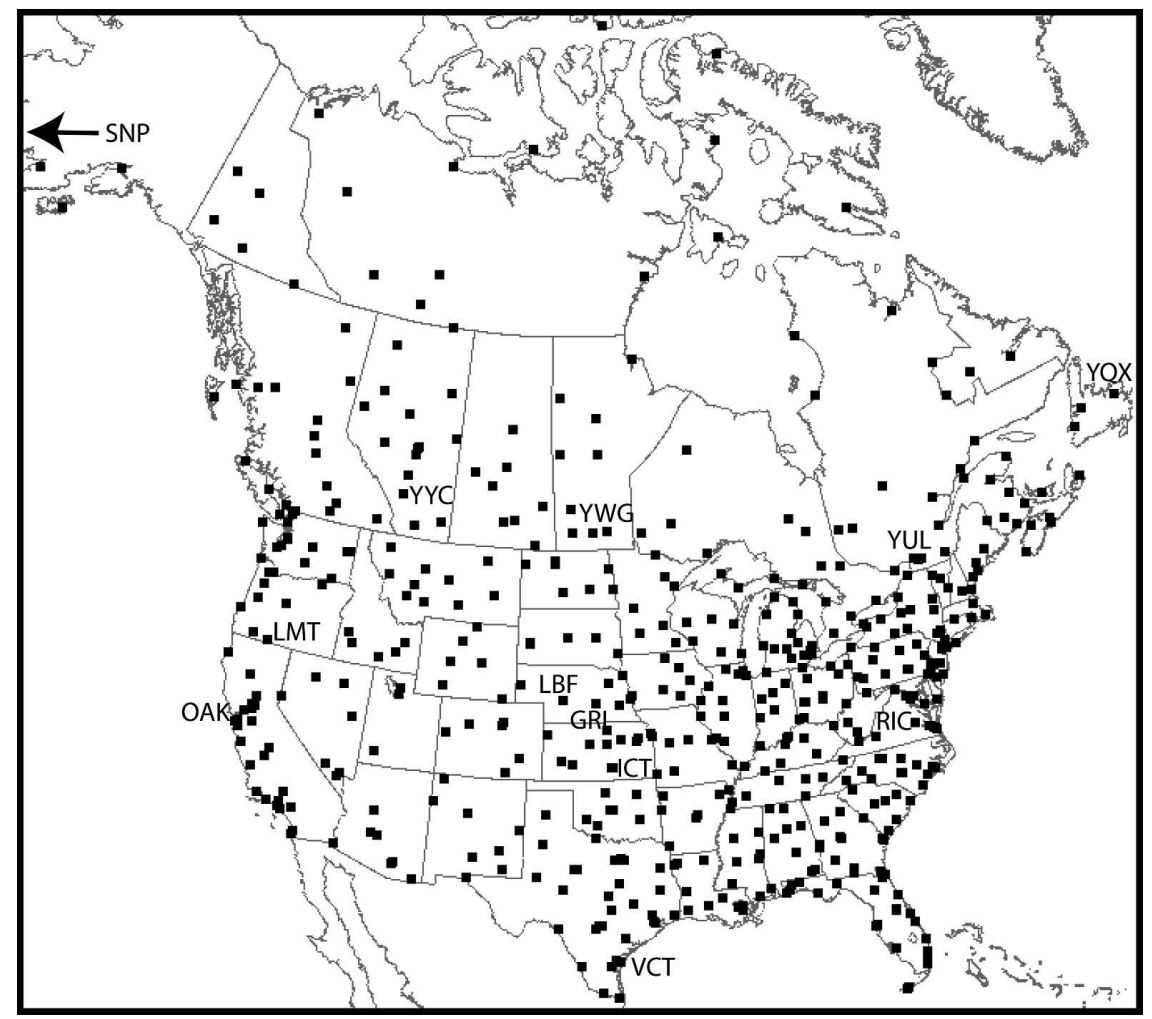

FIG. 1. Location of all of the stations in the United States and Canada used in the reduced dataset (584 stations). Stations discussed in the text are labeled. SNP is in the full (not reduced) dataset.

would reduce collision-coalescence frequencies, would reduce the likelihood of drizzle production, and could result in more persistent cloudiness. Other research has examined the effect that the concentration and size distribution of drizzle droplets in stratus clouds has on the earth's radiation budget (e.g., Feingold et al. 1999). Given the large areal extent of stratiform clouds on earth, small changes in the radiative properties of these clouds caused by changes in drizzle formation could have large impacts on the global climate.

To this end, one of the major challenges in global climate models (GCMs) is adequately simulating the diurnal patterns of the occurrence, frequency, and intensity of these light precipitation events (e.g., Dai and Trenberth 2004). Increased understanding of such patterns can potentially improve the distribution and temporal variation of atmospheric cloudiness, the radiation balance, and surface temperature variations in GCMs. One program, the National Center for Atmospheric Research Water Cycle Across Scales Initiative, examines the diurnal cycle of precipitation as a means of improving forecasts of large-scale precipitation changes in GCMs (Trenberth et al. 2003).

Despite the importance of drizzle to climate model- ing, little information exists about its observed spatial and temporal variability in the United States and Canada. Petty (1995) used the Comprehensive OceanAtmosphere Data Set (COADS) to show the occurrence and seasonal cycle of drizzle over the oceans. His Fig. 17 shows maxima of drizzle in the eastern ocean basins of the Northern and Southern Hemispheres and across the Southern Ocean, regions known to have persistent stratus and stratocumulus (e.g., Klein and Hartmann 1993; Rozendaal et al. 1995). Dai (2001a,b) examined the worldwide distribution of frequency of precipitation using 3-h synoptic weather reports over land and the COADS dataset over the ocean. He found similar maxima of drizzle occurrence over the oceans as Petty (1995) did, as well as maxima over the southeast United States, western Europe, and eastern South America (Dai 2001a, his Figs. 4, 5).

The purpose of the present study is to extend Dai's $(2001 \mathrm{a}, \mathrm{b})$ results by presenting a climatology of nonfreezing drizzle (hereafter drizzle, unless otherwise specified) over the United States and Canada in greater spatial and temporal detail. The dataset used in this study is described in section 2. Section 3 presents the annual cycle of drizzle for stations across the United 
States and Canada, whereas section 4 presents the diurnal cycle of drizzle. Section 5 illustrates the surface characteristics (sea level pressure, wind direction and speed, and visibility) associated with drizzle, demonstrating that drizzle can occur under a wide range of atmospheric conditions. Finally, section 6 summarizes the results of this paper.

\section{Data}

Drizzle is defined by the U.S. National Weather Service (NOAA 1995) as "fairly uniform precipitation composed exclusively of fine drops with diameters of less than $0.5 \mathrm{~mm}$ very close together." The surface dataset was constructed in the same manner as that of the freezing precipitation climatologies of Robbins and Cortinas (2002) and Cortinas et al. (2004) - that is, by merging two surface datasets from the National Oceanic and Atmospheric Administration/National Climatic Data Center (NOAA/NCDC; DATSAV2 and TD-3280) into a single format. The $15-\mathrm{yr}$ period from 1976 to 1990 was selected to ensure consistency among the data, maximize the number of stations with hourly surface data, and avoid the Automated Surface Observing System (ASOS) era. Before 1976, some station data were digitized every $3 \mathrm{~h}$ rather than hourly, and we desired the higher temporal resolution of the hourly data. By 1990, some National Weather Service stations in the United States had begun using ASOS instead of a human observer to take present weather conditions. Unfortunately, the ASOS system initially did not report drizzle because the precipitation identification sensor was not designed to detect drizzle-sized hydrometeors (e.g., Wade 2003). The resulting dataset, called the full dataset, contained 1376908 surface observations of nonfreezing drizzle from 1879 weather stations.

Following the methodology of Robbins and Cortinas (2002), stations that reported at least $80 \%$ of the possible surface observations were separated into a reduced dataset. This reduced dataset consisted of 692790 observations of nonfreezing drizzle from 584 stations (Fig. 1). About eight stations that did not report hourly still met the $80 \%$ criteria and were included in this reduced dataset. Unless otherwise noted, the reduced dataset was used throughout this work.

Some statistics from a freezing drizzle dataset were provided by J. Cortinas (Cortinas et al. 2004). This dataset consisted of 94767 observations of freezing drizzle from 605 stations. Combining this dataset with our reduced dataset produced 787557 observations of total drizzle, of which $88 \%$ were nonfreezing drizzle. Gridded maps of the spatial distribution of nonfreezing drizzle frequency were constructed using a two-pass Barnes objective analysis scheme (Koch et al. 1983).

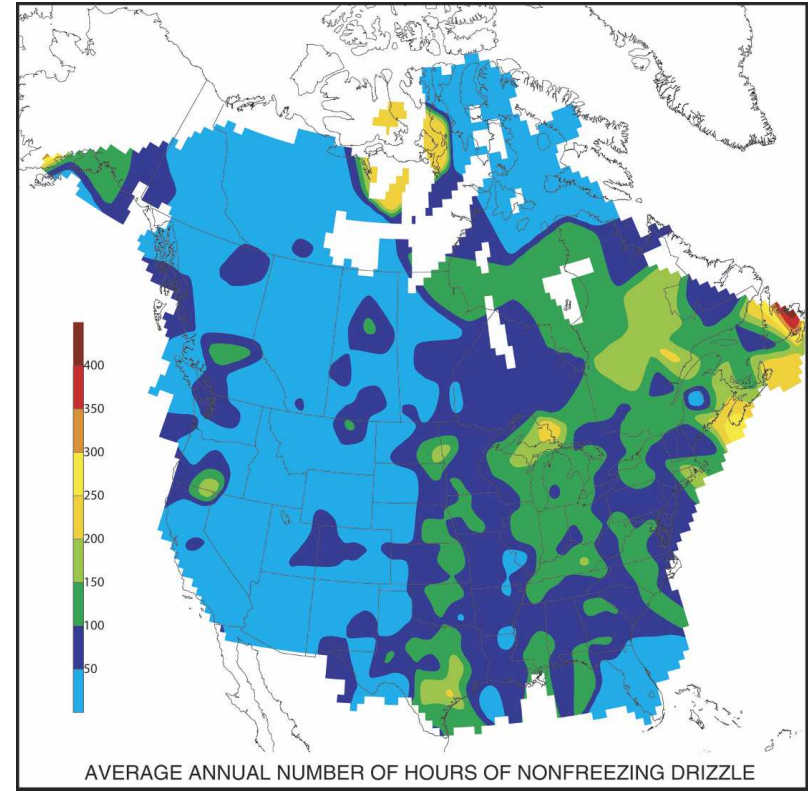

FIG. 2. Average annual number of hours of nonfreezing drizzle from the reduced dataset.

\section{Annual cycle}

In the United States and Canada, most nonfreezing drizzle falls in the central and eastern portions of the region (Fig. 2). The stations in the full dataset averaging the most drizzle each year are Gander, Newfoundland (YQX), Canada, and St. Paul Island, Alaska (SNP), in

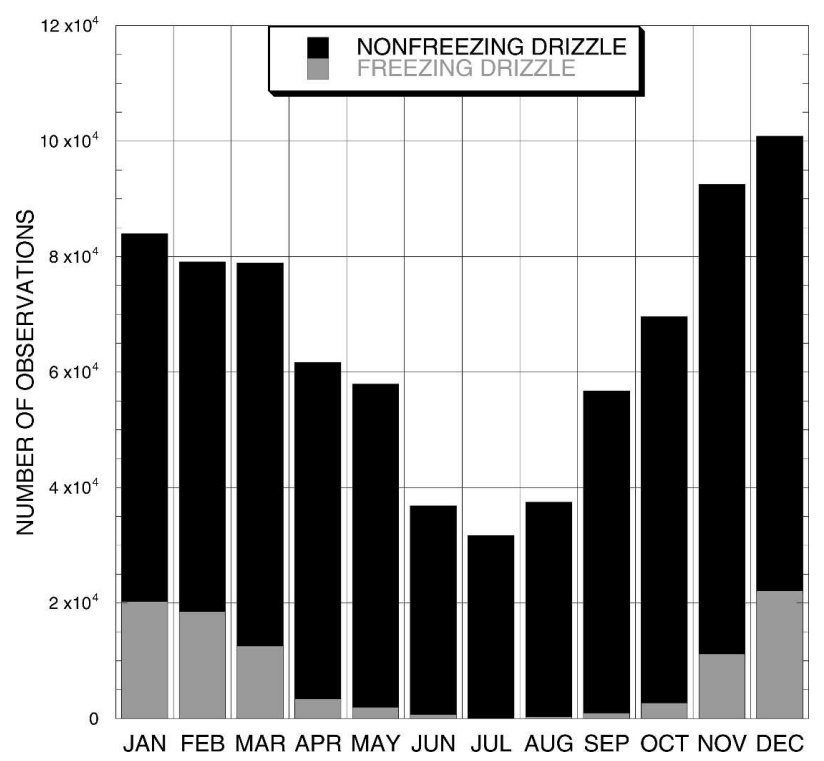

FIG. 3. Number of drizzle observations by month. Nonfreezing drizzle comes from the reduced dataset; freezing drizzle data is courtesy of J. Cortinas. 


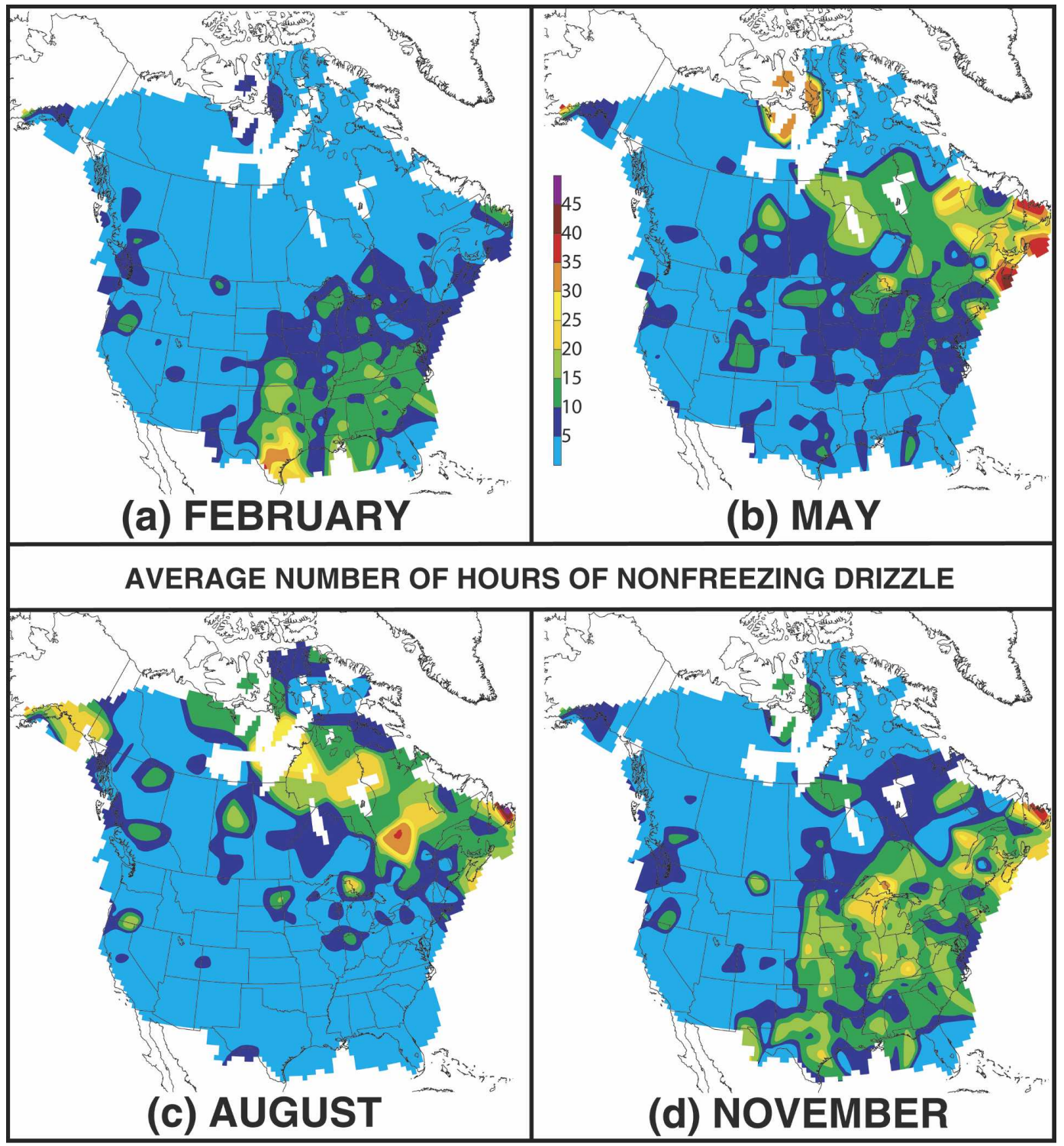

FIG. 4. Average number of hours of nonfreezing drizzle from the reduced dataset in (a) February, (b) May, (c) August, and (d) November.

the Pribilof Islands in the Bering Sea. Gander and St. Paul Island experience an annual average of 477 and $403 \mathrm{~h}$ of drizzle, respectively. When $80-100 \mathrm{~h}$ of freezing drizzle annually is included (Stuart and Isaac 1999, their Fig. 4; Cortinas et al. 2004, their Fig. 2c), Gander experiences about $560 \mathrm{~h} \mathrm{yr}^{-1}$ of total drizzle (both freezing and nonfreezing). Drizzle typically occurs less than $50 \mathrm{~h} \mathrm{yr}^{-1}$ in peninsular Florida and the high plains and western mountains of North America (Fig. 2).

One of the most distinguishing characteristics of Fig. 2 is the long, pronounced gradient of drizzle starting at northern Manitoba, Canada, south along $100^{\circ} \mathrm{W}$, and ending near the Texas-Mexico border. For example,
North Platte, Nebraska (LBF), averages 7 h of drizzle per year, whereas Grand Island, Nebraska (GRI), 236 $\mathrm{km}$ away, averages $124 \mathrm{~h}$ of drizzle per year, representing a gradient in drizzle frequency roughly an hour a year over $2 \mathrm{~km}$ ! This gradient in drizzle frequency mirrors that of surface dewpoint temperature (e.g., Dodd 1965), precipitation amount (e.g., Adler et al. 2003, their Fig. 9), heavy-rain events (e.g., Hershfield 1961; Brooks and Stensrud 2000, their Fig. 5; Schumacher and Johnson 2005, their Fig. 2), stratus clouds (e.g., available online at http://www.atmos.washington.edu/ 〜ignatius/CloudMap), and low clouds (available online at http://isccp.giss.nasa.gov/products/browsed2.html). 


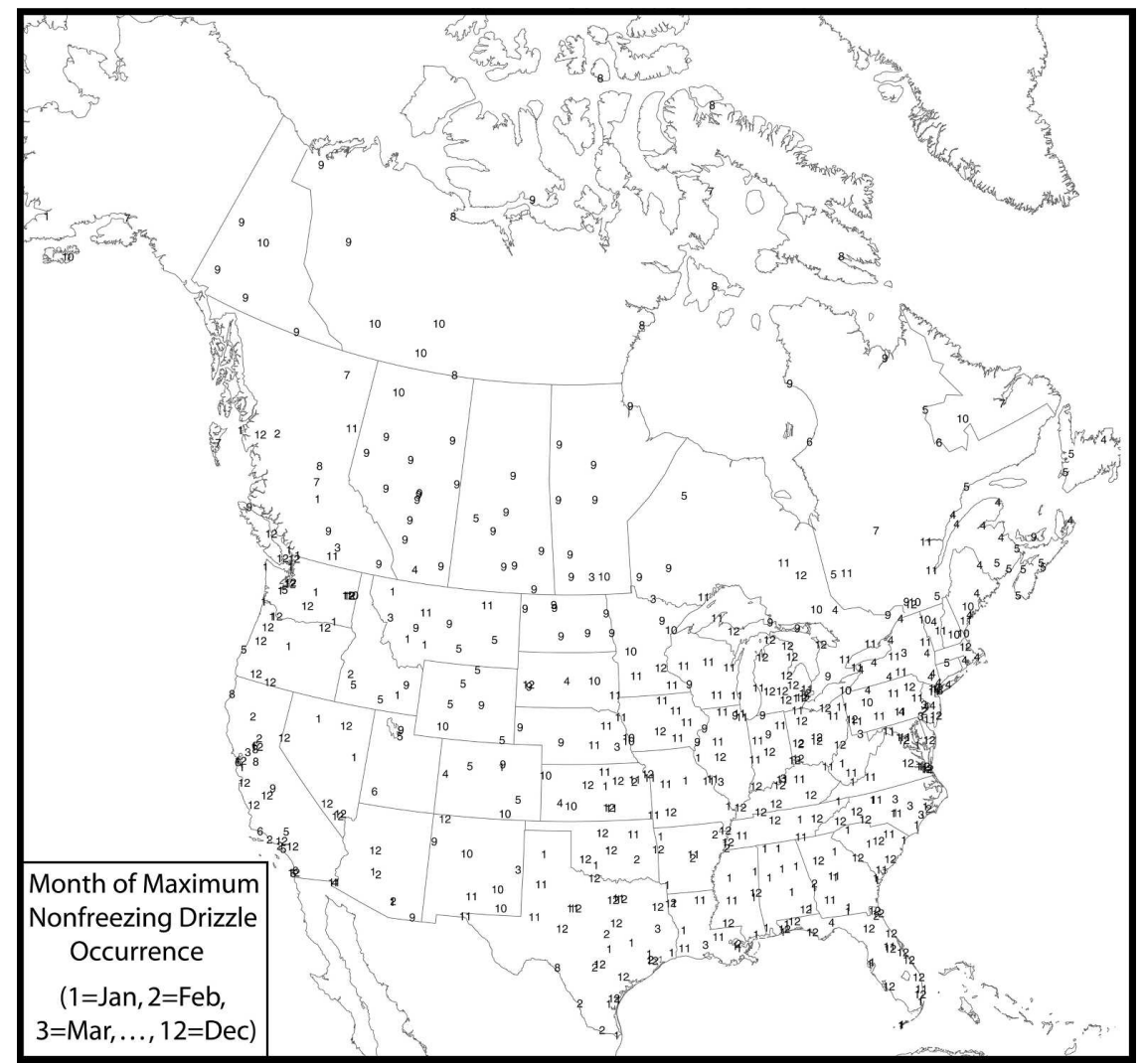

FIG. 5. Month of maximum nonfreezing drizzle occurrence $(1=$ January, $2=$ February, $3=$ March, ..., 12 = December $)$.

Such similarities between these fields suggest that the availability of low-level moisture may be related to this strong, geographically extensive gradient, although the exact reason for this remarkable gradient remains undetermined at this time.

A monthly distribution of nonfreezing drizzle using the reduced dataset, plus the statistics from the freezing drizzle dataset provided by J. Cortinas, shows that the most active month for total drizzle (nonfreezing and freezing) across the United States and Canada is December with $10.8 \%$ of the total drizzle observations, and the least active month is July with $6.2 \%$ of the observations (Fig. 3). Fall and early winter (September-December) have more total drizzle observations than spring. Greater tropospheric instability in the spring results in the more active spring severe-weather season (e.g., Doswell and Bosart 2001, p. 55; Brooks et al. 2006), implying less potential for drizzle than during the fall.

An animation of the frequency of nonfreezing drizzle by month across the United States and Canada exists on the Internet (see online at http://www.cimms.ou.edu/ $\sim$ schultz/drizzle). In February (Fig. 4a), the regions of most frequent drizzle are in Texas and the central and southeast United States. By May, the most frequent drizzle locations migrate northward to eastern Canada and the central portions of the Northwest Territories (Fig. 4b). Further northward migration of the drizzle frequency occurs in August, along with an increase along coastal Alaska (Fig. 4c). By November, drizzle frequency returns equatorward over most of the eastern United States and southeast Canada (Fig. 4d). The months of maximum drizzle occurrence tend to be April and May in the Canadian maritime provinces, September in the Canadian prairies, November in the upper Midwest, and December in the Ohio River Valley, Florida, Pacific coast, Texas, and Oklahoma (Fig. $5)$. Forty percent of the stations in the full dataset have a drizzle maximum from November to January.

In Canada, there is a transition in the month of maximum drizzle from east to west across the country from December at Montreal, Quebec (YUL), to October at Winnipeg, Manitoba (YWG), to September at Calgary, Alberta (YYC; Fig. 6). Since the eastern part of Canada has higher temperatures during the winter than the central part of the country due to the moderating effects of the Atlantic Ocean, we speculate that near-surface temperatures are more conducive to freezing drizzle than 


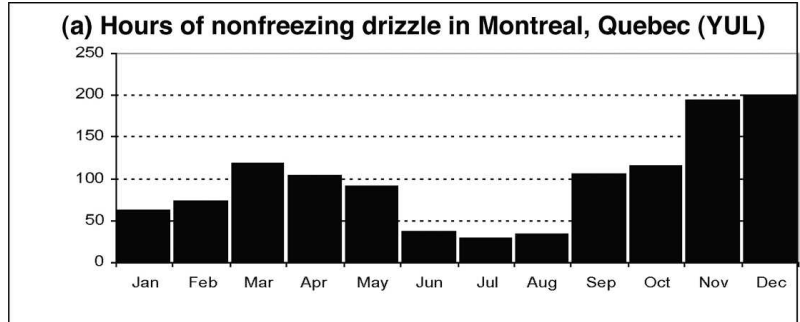

(b) Hours of nonfreezing drizzle in Winnipeg, Manitoba (YWG)

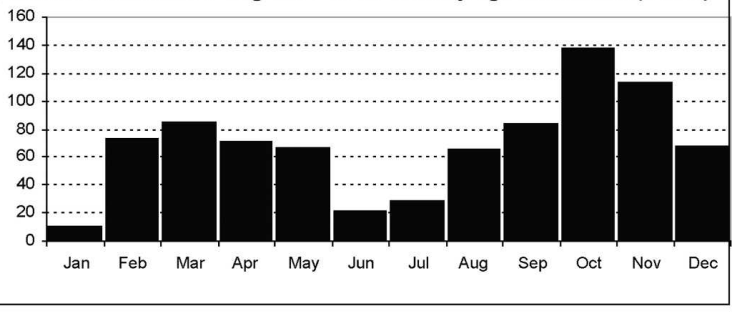

(c) Hours of nonfreezing drizzle in Calgary, Alberta (YYC)

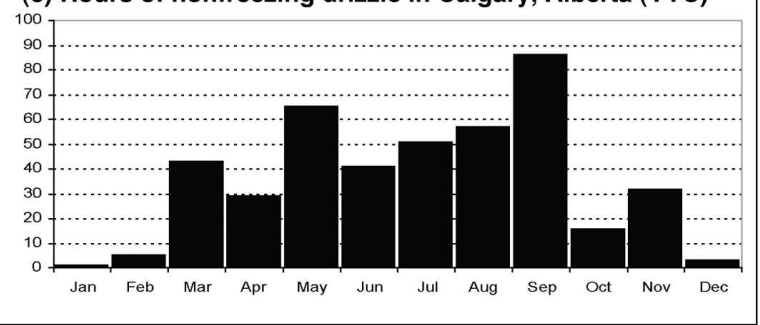

FIG. 6. Average number of hours of nonfreezing drizzle each month in (a) Montreal, QC, (b) Winnipeg, MB, and (c) Calgary, AB. Station locations are shown in Fig. 1.

warm drizzle during the winter in central Canada. These results are consistent with those of Cortinas et al. (2004, their Fig. 2), who showed a maximum of freezing drizzle in central Canada. This effect, however, does not amount to more than $15 \mathrm{~h}$ per month during the winter (Cortinas et al. 2004, their Fig. 8), so that the minimum in nonfreezing drizzle in the winters at Winnipeg and Calgary (Figs. 6b,c) is also a minimum in total drizzle, even if freezing drizzle was included.

These results in Fig. 5 are broadly consistent with those of Dai (2001a, his Figs. 4, 10b), ${ }^{1}$ who found that the frequency of drizzle peaked in the winter [December-February (DJF)] over the United States, particularly the eastern United States, and peaked in the summer [June-August (JJA)] over Canada and Alaska. Furthermore, Dai (2001a) showed that the seasonal cycle was relatively weak (explaining only $12 \%$ of the variance in the frequency of drizzle). Some stations from our dataset (e.g., Fig. 6) show bimodal distribu-

\footnotetext{
${ }^{1}$ There is an error in Fig. 10b of Dai (2001b): the spatial field of EOFs should be multipled by -1 (A. Dai 2005, personal communication).
}

tions with drizzle frequency exhibiting two relative maxima each year. Nevertheless, our results provide much more detailed spatial and temporal structures than those of Dai (2001a). The spatial distribution of drizzle throughout the year is also broadly consistent with the monthly occurrence of stratus and low clouds from online cloud datasets (e.g., see online at http:// www.atmos.washington.edu/ ignatius/CloudMap and http://isccp.giss.nasa.gov/products/browsed2.html).

\section{Diurnal cycle}

An animation of the diurnal cycle of drizzle over the United States and Canada exists on the Internet (http:// www.cimms.ou.edu/ schultz/drizzle). Most drizzle observations occur between 1200 and 1500 UTC (Fig. 7), although relative maxima appear on the synoptic hours every $3 \mathrm{~h}$, possibly related to the tendency for enhanced reporting of observed weather during this time. Furthermore, underreporting of drizzle at night may occur because human observers would be required to view the drizzle falling, which may be difficult in the dark. The most active hour for drizzle tends to be 1000-1100 UTC (0500-0600 LST) in eastern North America, 1100-1200 UTC (0500-0600 LST) in the midsection of the continent, and 1400-1500 UTC (0600-0700 LST) in the west (Fig. 8). To illustrate this effect, consider three stations (Richmond, Virginia; Wichita, Kansas; and Oakland, California) across the United States at nearly the same latitude (Fig. 9). Although Richmond (RIC) shows a subtle diurnal cycle, the peak hour is

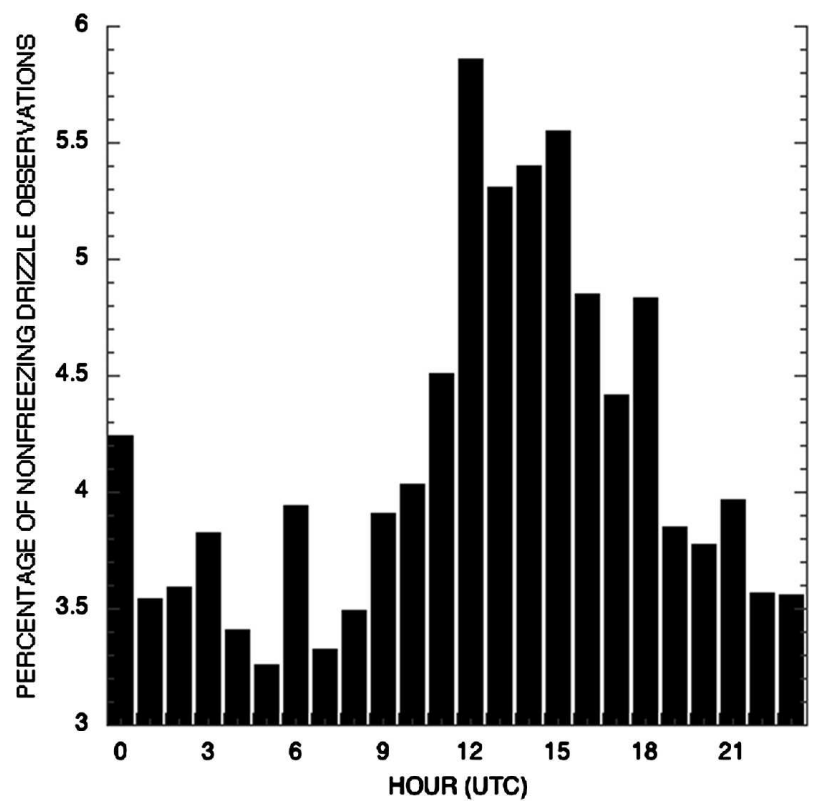

FIG. 7. Percent of nonfreezing drizzle observations from the full dataset by hour (UTC). 


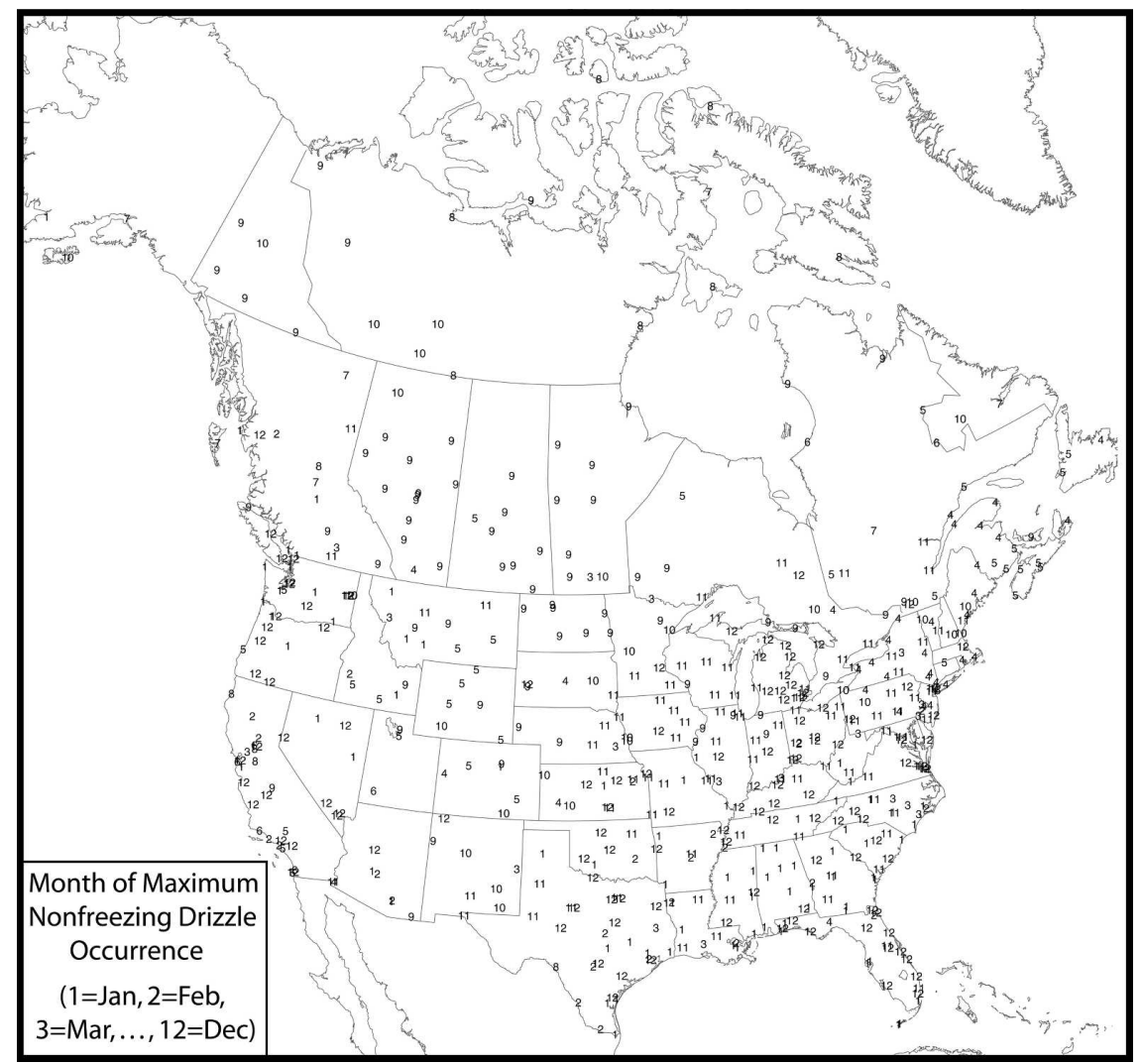

FIG. 8. Hour (UTC) of maximum nonfreezing drizzle occurrence.

0900 UTC (0400 LST; Fig. 9a). In contrast, Wichita (ICT) has a more pronounced diurnal cycle, with a peak at 1100 UTC (0500 LST; Fig. 9b). On the west coast of North America, Oakland (OAK) has a striking diurnal cycle peaking at 1500 UTC (0700 LST), with nearly no drizzle reported overnight between 2300 and 0400 UTC (1500 and 2000 LST; Fig. 9c).

An analysis of two of the drizzle maxima from Fig. 2 [Victoria, Texas (VCT in Fig. 1), and Klamath Falls, Oregon (LMT in Fig. 1)] indicates that there is substantial variability in the hourly distribution of drizzle in high-frequency drizzle locations (Fig. 10). Drizzle in Victoria gradually increases from 0200 to 1300 UTC (2000 to 0700 LST), but in Klamath Falls, the increase in drizzle frequency in the morning occurs more rapidly and later in the day, from 1000 to 1400 UTC (0200 to 0600 LST). The reason for the sharper morning increase in drizzle at Klamath Falls is unclear.

We speculate that the shift of the hour of maximum drizzle from east to west (Figs. 7-9), as well as the relative maxima at individual stations (e.g., Fig. 10), suggests a relationship between sunrise and the diurnal cycle. Cortinas et al. (2004, their Fig. 9) found a similar diurnal cycle for freezing drizzle over land. They ob- served that the occurrence of freezing drizzle is at a minimum in the afternoon, increasing overnight to a sharp peak just before sunrise. Dai (2001b) found that drizzle is most frequent at 0600 LST over land areas, similar to the results from the present study, and from midnight to 0400 LST over the oceans. Dai's (2001b) results for the ocean are consistent with those of Bretherton et al. (2004) for a region west of South America over the subtropical and tropical South Pacific Ocean. Dai (2001b) suggested that diurnal variations in relative humidity (primarily due to the cooler temperatures in the morning) contribute to this morning maximum over land, although he did not elaborate on the mechanism. One hypothesis is that the morning increase in solar insolation produces enough boundary layer and cloud-level turbulence to enhance the collision-coalescence processes that produce drizzle (e.g., Pinsky and Khain 1997; Vohl et al. 1999). A second hypothesis may be related to drizzle production in marine stratocumulus when drizzle tends to peak before sunrise. In such situations, the stratocumulus thickens overnight, favoring collision-coalescence and drizzle. Less low-level moisture over land may mean that this process is retarded relative to that over the oceans. 


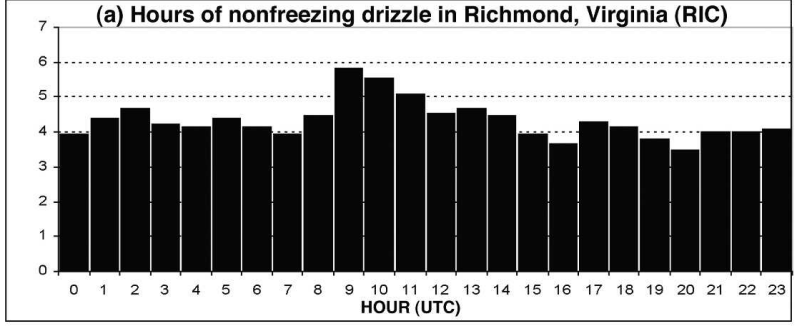

(b) Hours of nonfreezing drizzle in Wichita, Kansas (ICT)
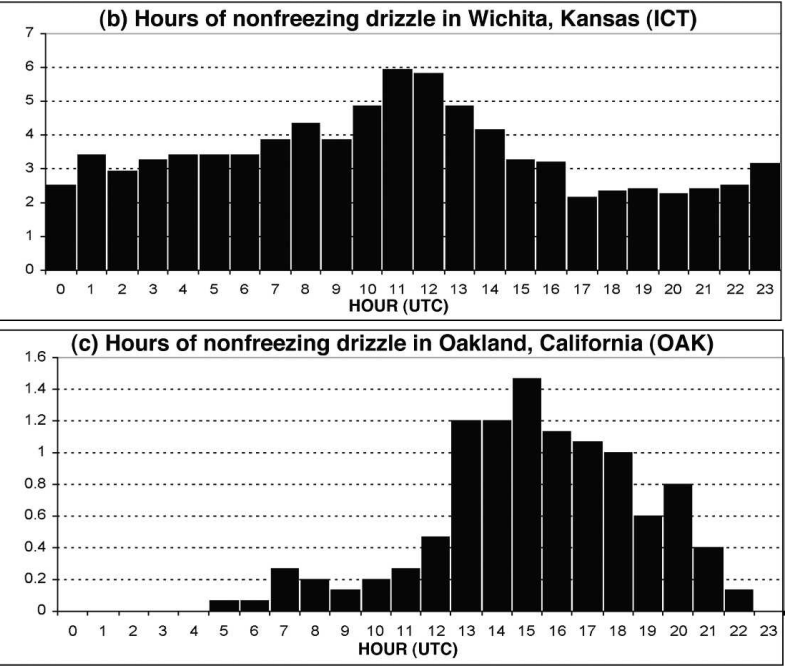

FIG. 9. Average number of hours of nonfreezing drizzle for each hour (UTC) in (a) Richmond, VA, (b) Wichita, KS, and (c) Oakland, CA. Station locations are shown in Fig. 1.

Given that some stations exhibit a steep increase in drizzle occurrence near sunrise (e.g., Figs. 9c, 10b), whereas other stations exhibit a gentle increase throughout the night (e.g., Fig. 10a), different processes may be occurring in different locations or under different synoptic regimes. Both of these hypotheses are highly speculative, and further research on the factors affecting these differing diurnal cycles at different locations would hopefully shed some light on the relevant processes.

\section{Meteorological conditions associated with drizzle}

Drizzle occurs during a variety of different surface atmospheric conditions. In this section, the distribution of drizzle as a function of surface weather observations that occur simultaneously with the drizzle is examined.

Drizzle occurs over a wide range of sea level pressures, from below $960 \mathrm{hPa}$ to above $1040 \mathrm{hPa}$ (Fig. 11a), indicating that a variety of synoptic-scale patterns are associated with the formation of drizzle. Most drizzle occurs at higher than normal sea level pressure, with more than $64 \%$ occurring at $1015 \mathrm{hPa}$ or greater (Fig. 11a). Drizzle also shows a preference for wind direction (Fig. 11b). Drizzle occurs most frequently (31.9\%)

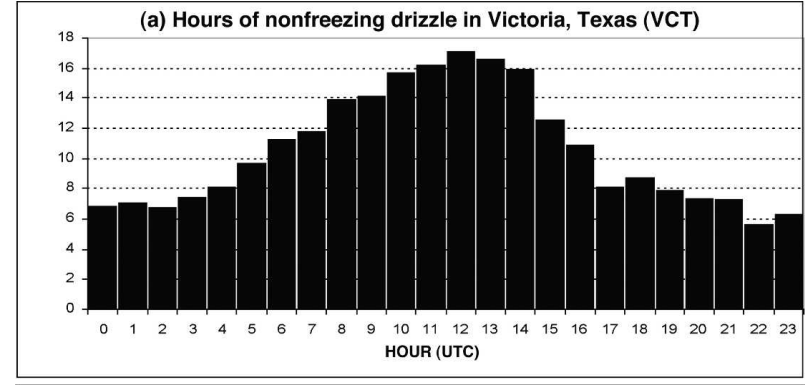

(b) Hours of nonfreezing drizzle in Klamath Falls, Oregon (LMT)

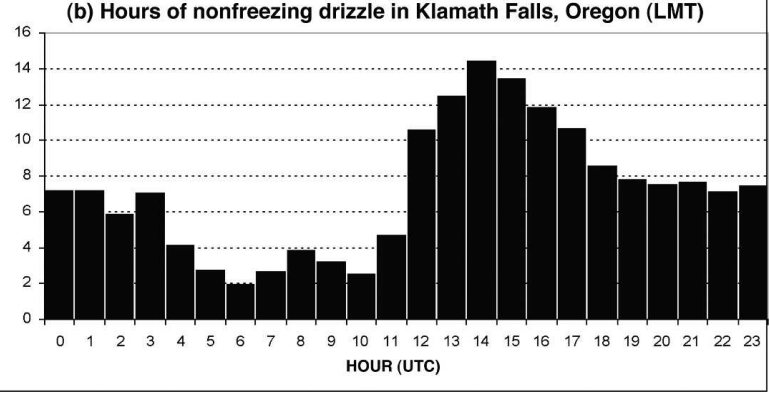

FIG. 10. Same as in Fig. 9, but in (a) Victoria, TX, and (b) Klamath Falls, OR.

when winds are from the northeast quadrant $\left(360^{\circ}-\right.$ $\left.89^{\circ}\right)$. The next most frequent quadrants are the southeast $\left(90^{\circ}-179^{\circ}\right)$ and the northwest $\left(270^{\circ}-359^{\circ}\right)$, with $23.9 \%$ and $20.0 \%$, respectively. Drizzle occurs least frequently $(16.6 \%)$ in the southwest quadrant $\left(180^{\circ}-269^{\circ}\right)$. These results suggest that drizzle commonly occurs north of a surface frontal boundary (say, a warm front) in a region of high surface pressure, as might be indicative of an anticyclone north of the frontal boundary. That drizzle occurs with a wide range of sea level pressures and wind directions indicates that a wide variety of weather regimes for drizzle occurrence is possible.

Wind speeds associated with drizzle are generally light, with $7.6 \%$ occurring under calm conditions (Figs. $11 \mathrm{~b}, \mathrm{c})$. Such situations may be associated with the weak winds around surface anticyclones, as discussed in the previous paragraph. Two-thirds of drizzle occurs with wind speeds $2.0-6.9 \mathrm{~m} \mathrm{~s}^{-1}$, with about $5 \%$ at wind speeds $\geqslant 10 \mathrm{~m} \mathrm{~s}^{-1}$ (Fig. 11c). Finally, $61 \%$ of all drizzle occurs with visibilities between 1.5 and $5.0 \mathrm{~km}$, with only $19.6 \%$ of drizzle at visibilities less than $1.5 \mathrm{~km}$ (Fig. 11d), roughly the minimum visibility required for visual flight rules (VFR) conditions for pilots. These results imply that although drizzle is associated with reduced visibility, the conditions are not commonly a visibility hazard, especially for aviation concerns.

\section{Conclusions}

The purpose of this paper is to examine the spatial and temporal variability of nonfreezing drizzle across 

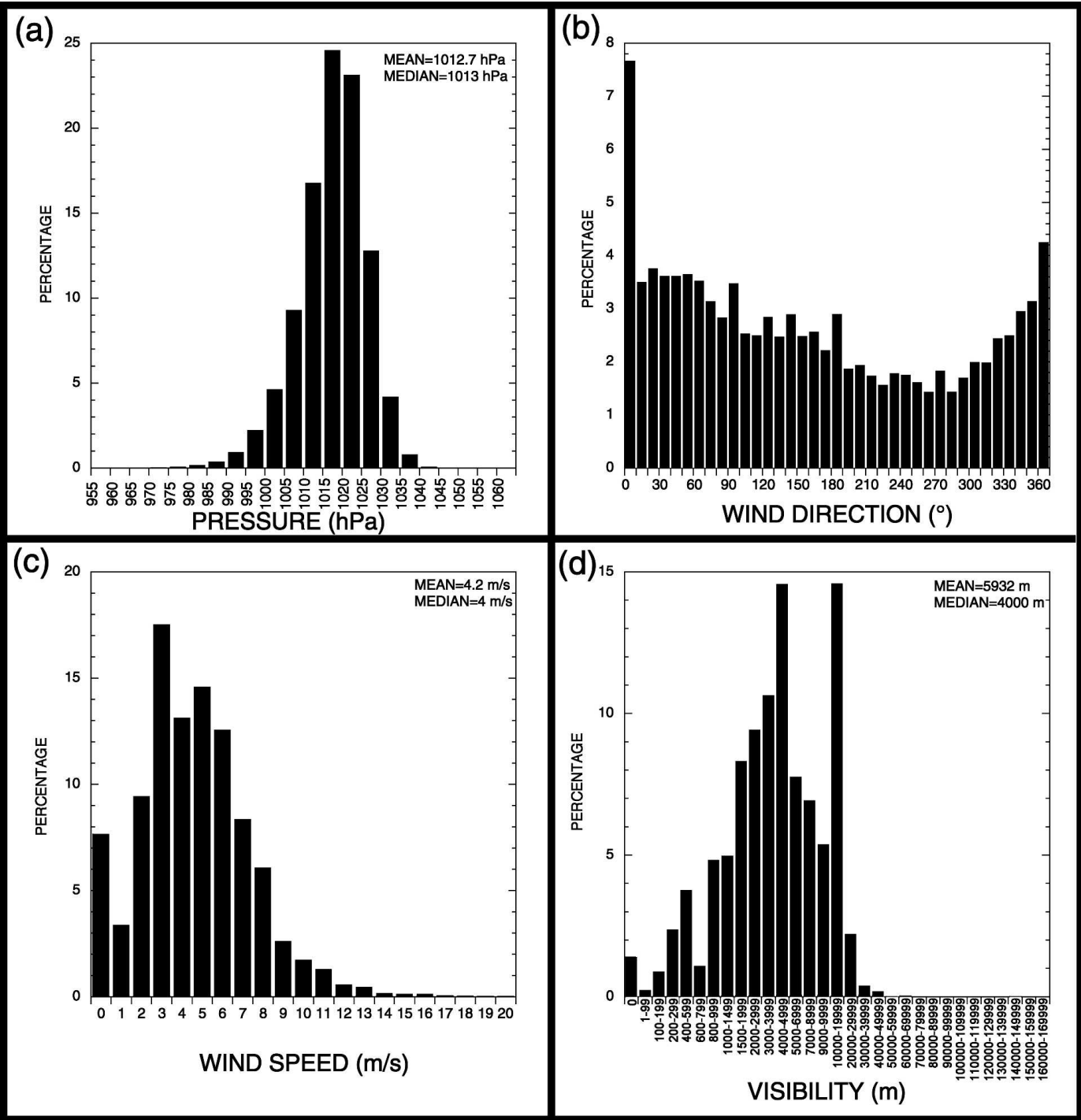

FIG. 11. Distributions of surface weather parameters associated with nonfreezing drizzle from the full dataset: (a) sea level pressure $(\mathrm{hPa}),(\mathrm{b})$ wind direction $\left(^{\circ}\right)$, (c) wind speed $\left(\mathrm{m} \mathrm{s}^{-1}\right)$, and (d) visibility $(\mathrm{m})$. Wind direction of $0^{\circ}$ is associated with calm winds in (b), and other bins are in $10^{\circ}$ intervals (e.g., the bin labeled 10 represents $10^{\circ}-19^{\circ}, \ldots$, the bin labeled 360 represents $1^{\circ}-9^{\circ}$ and $360^{\circ}$, which is due north). Percent of nonfreezing drizzle observations in the full dataset reporting the given parameter: sea level pressure $=58.0 \%$, wind direction and speed $=68.5 \%$, and visibility $=48.2 \%$.

the United States and Canada. Hourly surface data from 584 stations during 1976-90 served as the principal dataset for this study. This section summarizes the results of the analysis of that dataset.

Eighty-eight percent of all drizzle observations are nonfreezing drizzle. The number of nonfreezing drizzle observations across the United States and Canada exhibit an annual cycle with a maximum in November and a minimum in July. Most locations in the eastern United States and Canada experience frequent drizzle occurrence (50-200 h a year). Except for coastal
Alaska, central British Columbia, Canada, and a few western United States locations, drizzle occurs relatively infrequently (less than $50 \mathrm{~h}$ a year) throughout much of peninsular Florida, the western United States, and Canada. A strong gradient in drizzle frequency along $100^{\circ} \mathrm{W}$ separates the relatively drizzle-abundant eastern half of North America from the relatively drizzle-sparse western United States and Canada.

A seasonal migration of drizzle occurrence happens whereby the most frequent drizzle locations are eastern Canada and the central portions of the Northwest Ter- 
ritories in August, most of the eastern United States and southeast Canada in November, southeastern Texas and the eastern United States in February, and eastern Canada in May.

Drizzle also exhibits an identifiable diurnal cycle. Drizzle occurrence tends to peak just before sunrise, in agreement with other studies (e.g., Dai 2001b; Cortinas et al. 2004). The mechanism for this early morning maximum, however, remains unresolved.

Drizzle occurs during a wide range of surface atmospheric conditions from pressures less than $960 \mathrm{hPa}$ to greater than $1040 \mathrm{hPa}$. Most drizzle, however, occurs at higher than normal sea level pressure when winds are light and from the northeast quadrant. Only $7.6 \%$ of drizzle occurs in calm winds. Most drizzle (61\%) occurs with visibilities between 1.5 and $5.0 \mathrm{~km}$, with only about $20 \%$ occurring at visibilities less than $1.5 \mathrm{~km}$. Future work will examine the regional variability and synoptic patterns associated with drizzle over North America using this dataset.

Acknowledgments. We thank John Cortinas, Steve Fletcher, Doug Kennedy, and Chris Robbins for preparing and providing the surface dataset used in this study. John Cortinas also kindly provided statistics from his freezing drizzle dataset. We also thank Robert Coggins and Kim Elmore for their technical assistance. The second author benefited from advice and encouragement from Aiguo Dai, Sonia Lasher-Trapp, and Kevin Trenberth. David Mechem, Editor Anthony Del Genio, and two anonymous reviewers provided comments on earlier versions of this manuscript. This work was supported by the National Science Foundation for the National Weather Center Research Experiences for Undergraduates program under Grant 0097651. Funding for David M. Schultz was provided by NOAA/ OAR/NSSL under NOAA-OU Cooperative Agreement NA17RJ1227.

\section{REFERENCES}

Adler, R. F., and Coauthors, 2003: The Version-2 Global Precipitation Climatology Project (GPCP) monthly precipitation analysis (1979-present). J. Hydrometeor., 4, 1147-1167.

Albrecht, B. A., 1989: Aerosols, cloud microphysics, and fractional cloudiness. Science, 245, 1227-1230.

Bretherton, C. S., and Coauthors, 2004: The EPIC 2001 stratocumulus study. Bull. Amer. Meteor. Soc., 85, 967-977.

Brooks, H. E., and D. J. Stensrud, 2000: Climatology of heavy rain events in the United States from hourly precipitation observations. Mon. Wea. Rev., 128, 1194-1201.

— - A. R. Anderson, K. Riemann, I. Ebbers, and H. Flachs, 2006: Climatological aspects of convective parameters from the NCAR/NCEP reanalysis. Atmos. Res., in press.

Cortinas, J. V., Jr., B. C. Bernstein, C. C. Robbins, and J. W. Strapp, 2004: An analysis of freezing rain, freezing drizzle, and ice pellets across the United States and Canada: 1976-90. Wea. Forecasting, 19, 377-390.

Dai, A., 2001a: Global precipitation and thunderstorm frequencies. Part I: Seasonal and interannual variations. J. Climate, 14, 1092-1111.

_ 2001b: Global precipitation and thunderstorm frequencies. Part II: Diurnal variations. J. Climate, 14, 1112-1128.

_ and K. E. Trenberth, 2004: The diurnal cycle and its depiction in the Community Climate System Model. J. Climate, 17, 930-951.

Dodd, A. V., 1965: Dew point distribution in the contiguous United States. Mon. Wea. Rev., 93, 113-122.

Doswell, C. A., III, and L. F. Bosart, 2001: Extratropical synopticscale processes and severe convection. Severe Convective Storms, Meteor. Monogr., No. 50, Amer. Meteor. Soc., 27-69.

Feingold, G., B. Stevens, W. R. Cotton, and A. S. Frisch, 1996: The relationship between drop in-cloud residence time and drizzle production in numerically simulated stratocumulus clouds. J. Atmos. Sci., 53, 1108-1122.

_ W. W. Cotton, S. M. Kreidenweis, and J. T. Davis, 1999: The impact of giant cloud condensation nuclei on drizzle formation in stratocumulus: Implications for cloud radiative properties. J. Atmos. Sci., 56, 4100-4117.

Ferek, R. J., and Coauthors, 2000: Drizzle suppression in ship tracks. J. Atmos. Sci., 57, 2707-2728.

Frisch, A. S., C. W. Fairall, and J. B. Snider, 1995: Measurement of stratus cloud and drizzle parameters in ASTEX with $\mathrm{K}_{\alpha-}$ band Doppler radar and microwave radiometer. J. Atmos. Sci., 52, 2788-2799.

Galloway, J., and Coauthors, 1999: Coincident in situ and W-band radar measurements of drop size distribution in a marine stratus cloud and drizzle. J. Atmos. Oceanic Technol., 16, 504-517.

Gerber, H., 1996: Microphysics of marine stratocumulus clouds with two drizzle modes. J. Atmos. Sci., 53, 1649-1662.

Hershfield, D. M., 1961: Rainfall frequency atlas of the United States. U.S. Weather Bureau Tech. Paper 40, 115 pp.

Hudson, J. G., and S. S. Yum, 2001: Maritime-continental drizzle contrasts in small cumuli. J. Atmos. Sci., 58, 915-926.

Klein, S. A., and D. L. Hartmann, 1993: The seasonal cycle of low stratiform clouds. J. Climate, 6, 1587-1606.

Koch, S. E., M. DesJardins, and P. J. Kocin, 1983: An interactive Barnes objective map analysis scheme for use with satellite and conventional data. J. Climate Appl. Meteor., 22, 14871503 .

NOAA, 1995: Federal meteorological handbook no. 1, surface weather observations and reports. FCM-H1-1995, U.S. Dept. of Commerce, 405 pp. [Available online at http://www.ofcm. gov/fmh-1/fmh1.htm.]

Petty, G. W., 1995: Frequencies and characteristics of global oceanic precipitation from shipboard present-weather reports. Bull. Amer. Meteor. Soc., 76, 1593-1616.

Pinsky, M. B., and A. P. Khain, 1997: Turbulence effects on the collision kernel. Part I: Formation of velocity deviations of drops falling within a turbulent three-dimensional flow. Quart. J. Roy. Meteor. Soc., 123, 1517-1542.

Rasmussen, R. M., I. Geresdi, G. Thompson, K. Manning, and E. Karplus, 2002: Freezing drizzle formation in stably stratified layer clouds: The role of radiative cooling of cloud droplets, cloud condensation nuclei, and ice initiation. J. Atmos. Sci., 59, 837-860.

Robbins, C. C., and J. V. Cortinas Jr., 2002: Local and synoptic 
environments associated with freezing rain in the contiguous United States. Wea. Forecasting, 17, 47-65.

Rozendaal, M. A., C. B. Leovy, and S. A. Klein, 1995: An observational study of diurnal variations of marine stratiform cloud. J. Climate, 8, 1795-1809.

Schumacher, R. S., and R. H. Johnson, 2005: Organization and environmental properties of extreme-rain-producing mesoscale convective systems. Mon. Wea. Rev., 133, 961-976.

Stevens, B., and Coauthors, 2003: Dynamics and chemistry of marine stratocumulus-DYCOMS-II. Bull. Amer. Meteor. Soc., 84, 579-593.

G. Vali, K. Comstock, R. Wood, M. C. van Zanten, P. H. Austin, C. S. Bretherton, and D. H. Lenschow, 2005: Pockets of open cells and drizzle in marine stratocumulus. Bull. Amer. Meteor. Soc., 86, 51-57.

Stuart, R. A., and G. A. Isaac, 1999: Freezing precipitation in Canada. Atmos.-Ocean, 37, 87-102.

Trenberth, K. E., A. Dai, R. M. Rasmussen, and D. B. Parsons, 2003: The changing character of precipitation. Bull. Amer. Meteor. Soc., 84, 1205-1217.

Vohl, O., S. K. Mitra, S. C. Wurzler, and H. R. Pruppacher, 1999: A wind tunnel study of the effects of turbulence on the growth of cloud drops by collision and coalescence. J. Atmos. Sci., 56, 4088-4099.

Wade, C. G., 2003: A multisensor approach to detecting drizzle on ASOS. J. Atmos. Oceanic Technol., 20, 820-832. 